\title{
Penyusunan Model untuk Penangkapan Berkelanjutan Ikan Pelagis dengan Pendekatan Jenjang Trofik di Selat Makassar
}

\author{
Richardus Kaswadji ${ }^{*}$, Muhammad Hatta ${ }^{2)}$, dan Nur Asia Umar ${ }^{3)}$ \\ 1)Fakultas Perikanan dan IImu Kelautan, Institut Pertanian Bogor Kampus IPB-Darmaga, Bogor 16680 \\ 2)Fakultas IImu Kelautan dan Perikanan, Universitas Hasanuddin, Makassar \\ ${ }^{3}$ Fakultas Perikanan, Universitas Cokroaminoto, Makassar \\ Diterima 28-03-2009 Disetujui 20-04-2009
}

\begin{abstract}
Observations on pelagic fish catch activities using bagan Rambo in Makassar Strait had been conducted in 2005 and 2006 to obtain physical, chemical, and biological data and their processes in the operation of bagan Rambo in the observation sites. The objective of the study was to overcome the overfishing problems which have been happenning in Makassar Strait, using a model of the trophic level approaches. Nine observation stations were set in three transects perpendicular to the coast. The measurement of physical, chemical, and biological parameters were conducted monthly. Biological parameters measured were chlorophyll-a, and the abundance of phytoplankton and zooplankton. Phytoplankton primary productivity, grazing mortality of phytoplankton by zooplankton, number of catch of fish, and fish feeding habit were also measured. Run of the built model based on the data obtained showed that with the present catch-pressure (assuming that this was the start of catching operation), there would be an overfishing starting in the $26^{\text {th }}$ or $27^{\text {th }}$ month onward. Meanwhile, if the catch were half of the present, then there would be an overfishing in the $31^{\text {st }}$ or $32^{\text {nd }}$ month, but would back to the sustainable production months after that. The model is still being developed by finding and adding more accurate data and parameters.
\end{abstract}

Keywords: Bagan Rambo, Makassar Strait, modeling, overfishing

\section{PENDAHULUAN}

Salah satu masalah utama dalam pengelolaan sumberdaya perikanan di beberapa daerah di Indonesia adalah terjadinya eksploitasi yang berlebihan. Data di banyak perairan menunjukkan bahwa telah terjadi degradasi populasi yang berujung pada penurunan produksi akibat tangkap-lebih. Jika tangkap-lebih dilakukan pada jenjang trofik lebih rendah maka kegiatan tersebut akan mengurangi transfer biomassa pada jenjang trofik yang lebih tinggi. Dalam kondisi seperti itu, produktivitas primer fitoplankton yang tinggi pun tidak akan mampu mendukung jenjang trofik di atasnya.

Oleh karena itu dibutuhkan suatu kajian yang mempelajari saling keterkaitan multi faktor dan mengidentifikasi faktor kunci yang pengaruhnya besar terhadap struktur dan dinamika pada setiap jenjang trofik. Informasi tentang hal tersebut dapat dijadikan acuan dalam merumuskan model pengelolaan sumberdaya ikan yang berkelanjutan. Salah satu pendekatan adalah penetapan potensi daya dukung lingkungan pada jenjang trofik terendah sebagai

\footnotetext{
${ }^{*}$ Telp: +628161828675

Email: rkaswadji@yahoo.com
}

produser primer. Jika pemanfaatan sumberdaya ikan pada jenjang trofik yang lebih tinggi melebihi kapasitas daya dukung pada jenjang trofik di tingkat yang terendah, maka penangkapan yang berlebihan akan berdampak negatif dalam jangka lama, karena sumberdaya pada jenjang trofik lebih tinggi sangat ditentukan oleh kondisi jenjang trofik di bawahnya. Dengan demikian, diperlukan metode pendugaan yang dapat memberikan hasil yang lebih akurat. Salah satu alternatif yang mungkin dan didukung oleh konsep ilmiah adalah pendugaan potensi dan daya dukung pada jenjang trofik dasar berbasis produktivitas primer.

Sebagian besar nelayan di Sulawesi Selatan menangkap ikan di perairan Selat Makassar dengan mengoperasikan bagan Rambo. Arimoto et al., (2001) mengemukakan bahwa bagan merupakan salah satu alat tangkap yang menggunakan cahaya yang banyak digunakan di berbagai tempat di Indonesia dan negara lain. Alat tangkap ini telah mengalami modifikasi dan modernisasi, salah satu di antaranya adalah bagan Rambo yang banyak dioperasikan oleh nelayan di Sulawesi Selatan. Penelitian ini dilakukan pada operasi alat tangkap bagan tersebut. 
Pada daerah penangkapan, secara alamiah faktor oseanografi mengalami dinamika periodik musiman dalam setahun. Hal ini akan mempengaruhi kehidupan fitoplankton dan menentukan kapasitas daya dukung maksimal produksi primernya. Mengingat faktor alam sangat sulit atau bahkan tidak dapat dimodifikasi, maka praktis kapasitas daya dukung maksimal secara alamiah sulit dihitung dan diperkirakan.

Tujuan utama tulisan ini adalah untuk menyusun suatu model pendekatan jenjang trofik dalam upaya menanggulangi masalah tangkap-lebih di Selat Makassar. Pemodelan sudah banyak digunakan oleh peneliti lain untuk menggambarkan dinamika proses di alam yang karena sifatnya yang kompleks tidak mungkin melibatkan seluruh parameter yang terkait. Beberapa contoh misalnya pemodelan oleh Costanza et al., (1990) \& Parsons \& Kessler (1987) di Amerika Serikat serta Naito et al., (2001) di Jepang.

\section{BAHAN DAN METODE}

Penelitian dilaksanakan di daerah penangkapan bagan Rambo perairan pantai Kabupaten Barru, Selat Makassar, pada bulan Mei, Juni, Juli, September, Oktober, dan November 2005 pada posisi koordinat $4.32^{\circ}-4.48^{\circ}$ LS dan $119.38^{\circ}-119.59^{\circ}$ BT (Gambar 1). Penelitian difokuskan pada pengambilan data lapangan untuk mendapatkan data parameter oseanografi, distribusi dan kelimpahan plankton, jumlah dan kebiasaan ikan yang tertangkap dengan bagan Rambo.

Metode Pengambilan Contoh. Penentuan lokasi pengambilan contoh dilakukan berdasarkan penyebaran unit bagan Rambo. Seluruh wilayah dibagi dalam 3 (tiga) transek yang terdiri dari 3 stasiun pada setiap transek.

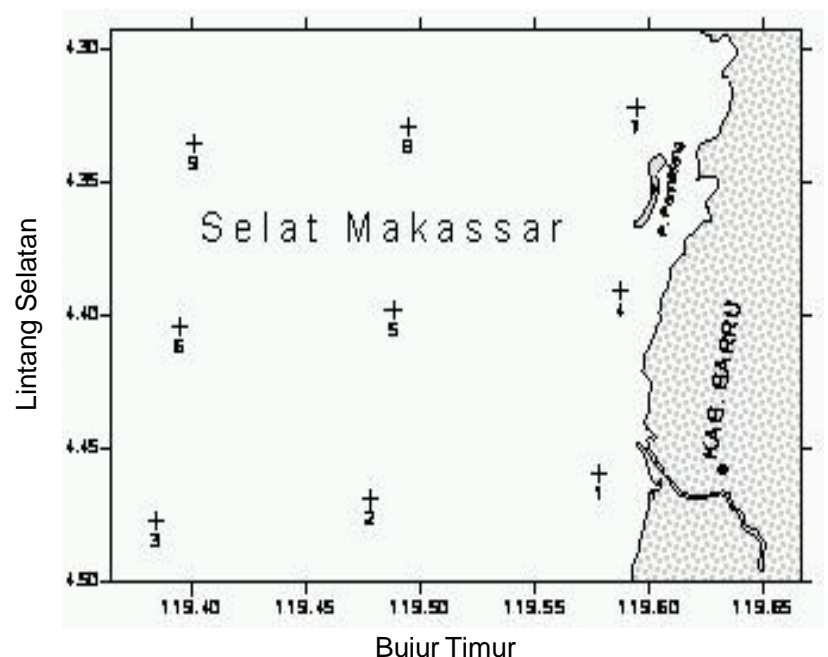

Gambar 1. Peta lokasi penelitian penangkapan bagan Rambo di Selat Makassar.
Posisi stasiun pada setiap transek dibuat tegak lurus dari pantai ke arah laut.

Pengukuran parameter suhu, salinitas, intensitas cahaya matahari, arah dan kecepatan arus, kecerahan, $\mathrm{pH}$, oksigen terlarut (DO), serta nutrien (fosfat, nitrat, dan silikat) dilakukan setiap bulan pada semua stasiun. Pengukuran suhu dan salinitas dilakukan secara vertikal dari kedalaman 0-75 $\mathrm{m}$ (sesuai kedalaman rata-rata fishing ground bagan Rambo) dengan interval $25 \mathrm{~m}$. Kadar oksigen terlarut dan nutrien diukur pada setiap kedalaman standar 0; 25; 50; dan 75 m. Parameter biologi yang diukur bersamaan pada stasiun oseanografi ini adalah klorofil-a, kelimpahan fitoplankton dan kelimpahan zooplankton.

Produktivitas primer ditentukan berdasarkan laju fotosintesis fitoplankton lewat suatu eksperimen dengan metode botol gelap dan botol terang (Kaswadji et al., 1993). Pengambilan contoh fitoplankton dan zooplankton dilakukan masing-masing dengan menyaring air laut sebanyak $90 \mathrm{~L}$ dengan net yang memiliki mata jaring $80 \mu \mathrm{m}$ untuk fitoplankton dan 300 $\mu \mathrm{m}$ untuk zooplankton.

Laju grazing (pemangsaan) populasi zooplankton terhadap populasi fitoplankton dilakukan untuk mengukur jumlah energi atau biomassa yang ditransfer dari fitoplankton ke zooplankton. Pengukuran ini dilakukan dengan kurungan dari jaring plankton net yang berbentuk kubus dengan ukuran $10 \times 10 \times 10$ $\mathrm{cm}^{3}$ dengan bingkai besi. Kurungan diisi dengan fitoplankton dan zooplankton yang didapatkan dari penyaringan komposit secara vertikal dari kedalaman $75 \mathrm{~m}$ sampai permukaan. Kurungan yang telah diisi fitoplankton dan zooplankton dimasukkan ke dalam kolom air (diinkubasi) pada kedalaman 0; 25; 50; dan $75 \mathrm{~m}$ selama 3 jam. Dengan membandingkan kelimpahan fitoplankton dan zooplankton antara sebelum dan sesudah inkubasi, laju pemangsaan dapat dihitung dan dinyatakan dalam satuan (sel fito)/(individu zoo)/hari atau (gr fito)/(gr zoo)/hari.

Jumlah tangkapan per jenis ikan ditentukan dari volume tangkapan per jenis ikan pada unit bagan. Untuk mengamati perubahan hasil tangkapan, data catatan harian pemilik bagan dikumpulkan kemudian dihitung totalnya setiap bulan. Kebiasaan makan ikan pelagis yang tertangkap ditentukan dari isi lambung yang dilakukan dengan cara mengambil sampel dari setiap jenis ikan setiap minggu. Metode yang digunakan dalam analisis isi lambung adalah metode gravimetrik, 
yaitu dengan mengidentifikasi dan menimbang berat setiap fraksi jenis makanan

Analisis Data. Struktur jenjang trofik setiap jenis ikan yang tertangkap dianalisis dengan menggunakan software TrophLab2K. Penentuan jenjang trofik suatu spesies ikan ditentukan berdasarkan komposisi makanan dan jenjang trofik masing-masing fraksi makanannya yang diperoleh dari hasil analisis isi lambung (Pauly et al., 2000). Nilai jenjang trofik suatu jenis ikan dinyatakan dengan formula berikut:

$$
\text { troph }=1+\sum_{\mathrm{j}=1}^{\mathrm{G}} \mathrm{DC}_{\mathrm{ij}} \cdot \text { troph }_{\mathrm{j}}
$$

Di mana $D C_{i j}$ adalah fraksi mangsa ke-i dalam makanan konsumer ke-j; troph $h_{j}$ adalah jenjang trofik ke-j dan $\mathrm{G}$ adalah jumlah group atau kelompok makanan. Perhitungan jenjang trofik ini mengacu pada konvensi Program Biologi Internasional yang menyepakati produser primer (fitoplankton) dan detritus (termasuk bakteri) dikategorikan dalam jenjang trofik 1 (Matthews et al., 1993) sementara zooplankton masuk kategori jenjang trofik 2.

Untuk menggambarkan dinamika jenjang trofik, hasil analisis data disintesis untuk dirumuskan dan dibuat beberapa sub model pada setiap jenjang trofik. Berdasarkan hasil analisis struktur jenjang trofik, dibentuk beberapa sub model dinamik yaitu: fitoplankton, zooplankton, ikan planktivor (pemakan plankton), ikan karnivor dan ikan omnivor. Untuk membuat masing-masing sub model digunakan alat bantu program Stella 5.0 dalam menghitung dan menduga parameter yang sulit didapatkan di lapangan seperti laju kematian alami ikan, pertumbuhan dan beberapa parameter dinamika populasi ikan lainnya (Christensen \& Pauly et al., 1993).

Untuk menjelaskan hubungan antara kelimpahan plankton dengan parameter oseanografi digunakan analisis regresi linier berganda (stepwise) antara kelimpahan fitoplankton $(\mathrm{Y})$ dengan beberapa parameter lingkungan di permukaan sebagai variabel penduga (X) diantaranya suhu, salinitas, $\mathrm{pH}$, kecepatan arus, dan kandungan nitrien (nitrat, fosfat, silikat).

\section{HASIL DAN PEMBAHASAN}

Suhu dan Salinitas. Rata-rata suhu perairan pada berbagai kedalaman paling tinggi dan paling bervariasi tercatat pada bulan Oktober sedangkan rata-rata suhu terendah terjadi pada bulan Juni (Tabel 1). Salinitas permukaan di perairan daerah penangkapan bagan Rambo dari bulan Mei sampai dengan Oktober 2005 berkisar antara $29-35 \%$ odengan rata-rata $31,31 \pm 1,49 \%$ 。 (Tabel 2).

Intensitas Cahaya dan Kecerahan. Hasil pengukuran intensitas cahaya dan kecerahan yang dilakukan pada stasiun oseanografi hanya tercatat pada siang hari dan pada stasiun tertentu saja. Data hasil pengukuran pada bulan Juni dan Juli menunjukkan perubahan intensitas cahaya harian mencapai

Tabel 1. Rata-rata \pm simpangan baku $(\mathrm{SB})$ suhu $\left({ }^{\circ} \mathrm{C}\right)$ perairan Selat Makassar pada berbagai kedalaman

\begin{tabular}{|c|c|c|c|c|c|c|c|c|c|c|c|c|}
\hline \multirow{3}{*}{$\begin{array}{c}\text { Bulan } \\
\text { Mei }\end{array}$} & \multicolumn{4}{|c|}{ Permukaan } & \multicolumn{4}{|c|}{25 meter } & \multicolumn{4}{|c|}{50 meter } \\
\hline & \multicolumn{3}{|c|}{ Rata-rata \pm SB } & \multirow{2}{*}{$\frac{n}{6}$} & \multicolumn{3}{|c|}{ Rata-rata \pm SB } & \multirow{2}{*}{$\frac{n}{6}$} & \multicolumn{3}{|c|}{ Rata-rata \pm SB } & \multirow{2}{*}{$\frac{n}{2}$} \\
\hline & 30,17 & + & 0,41 & & 28,33 & \pm & 0,82 & & & & & \\
\hline Juni & 27,86 & \pm & 0,97 & 9 & 27,21 & \pm & 0,72 & 9 & 26,60 & \pm & 0,35 & 3 \\
\hline Juli & 29,58 & \pm & 0,27 & 9 & 28,86 & \pm & 0,44 & 9 & 27,94 & \pm & 0,24 & 5 \\
\hline September & 29,72 & \pm & 0,29 & 9 & & & & - & & & & * \\
\hline Oktober & 31,07 & \pm & 0,90 & 9 & 29,58 & \pm & 1,52 & 9 & 29,93 & \pm & 1,50 & 5 \\
\hline
\end{tabular}

Tabel 2. Rata-rata \pm simpangan baku (SB) salinitas (\%o) perairan Selat Makassar pada berbagai kedalaman

\begin{tabular}{|c|c|c|c|c|c|c|c|c|c|c|c|c|}
\hline \multirow{3}{*}{$\begin{array}{c}\text { Bulan } \\
\text { Mei }\end{array}$} & \multicolumn{4}{|c|}{ Permukaan } & \multicolumn{4}{|c|}{25 meter } & \multicolumn{4}{|c|}{50 meter } \\
\hline & \multicolumn{3}{|c|}{ Rata-rata \pm SB } & \multirow{2}{*}{$\frac{n}{6}$} & \multicolumn{3}{|c|}{ Rata-rata $\pm S B$} & \multirow{2}{*}{$\begin{array}{l}n \\
6\end{array}$} & \multicolumn{3}{|c|}{ Rata-rata \pm SB } & \multirow{2}{*}{$\frac{n}{2}$} \\
\hline & 31,00 & + & 1,10 & & 31,50 & \pm & 1,76 & & 30,50 & \pm & 0,71 & \\
\hline Juni & 31,00 & \pm & 0,87 & 9 & 31,56 & \pm & 0,53 & 9 & 32,00 & \pm & 0,00 & 3 \\
\hline Juli & 30,67 & \pm & 0,50 & 9 & 30,56 & \pm & 0,53 & 9 & 30,40 & \pm & 0,55 & 5 \\
\hline September & 33,22 & \pm & 1,54 & 9 & & & & & & & & \\
\hline Oktober & 30,56 & \pm & 1,33 & 9 & 32,89 & \pm & 1,27 & 9 & 31,00 & \pm & 1,00 & 5 \\
\hline
\end{tabular}


maksimal antara jam 12:00 sampai dengan 14:00 (Gambar 2).

Oksigen Terlarut dan pH. Nilai kadar oksigen terlarut di permukaan perairan berkisar antara 3,3-9,7 ppm. Rata-rata kadar oksigen pada bulan Juni lebih tinggi dibandingkan dengan bulan Juli pada semua kedalaman. Nilai pH air permukaan pada semua stasiun berkisar antara 6,0-8,7 dengan rata-rata 7,18 0,67.

Kecepatan Arus dan Kadar Nutrien. Kecepatan arus permukaan di lokasi penelitian berkisar antara 0,05-0,21 meter/detik. Rata-rata kecepatan arus permukaan pada bulan Juni-September relatif sama atau lebih lambat dibandingkan dengan arus pada bulan Oktober (Tabel 3). Rata-rata kadar nitrat berdasarkan waktu pengamatan menunjukkan kecenderungan meningkat dari Mei hingga Juni, sebaliknya kadar fosfat

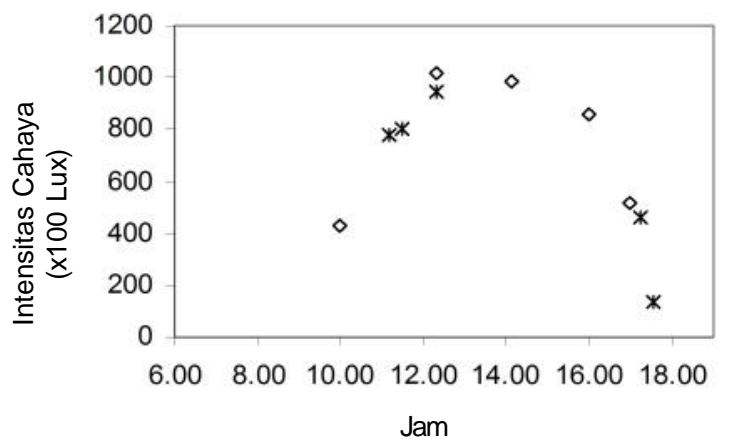

Gambar 2. Intensitas cahaya (100 lux) pada bulan Juni dan Juli di Selat Makassar. cenderung menurun. Kadar silikat relatif seragam baik antar stasiun maupun waktu pengamatan.

Plankton. Komposisi dan Kelimpahan Fitoplankton. Fitoplankton yang didapatkan selama penelitian terdiri dari empat Kelas, yaitu Bacillariophyceae (27 genus), Dinophyceae ( 7 genus), Cyanophyceae (2 genus) dan Chlorophyceae (1 genus). Seperti yang umum terdapat di laut, populasi fitoplankton didominasi oleh diatom. Rata-rata kelimpahan total fitoplankton berkisar antara $431 \mathrm{sel} / \mathrm{L}$ sampai dengan $5438 \mathrm{sel} / \mathrm{L}$ (Tabel 4).

Kelimpahan fitoplankton cenderung menurun dari bulan Mei sampai mencapai nilai terendah pada bulan September, kemudian meningkat pada bulan Oktober sampai mencapai puncak kelimpahan pada bulan November. Komposisi jenis masih konsisten

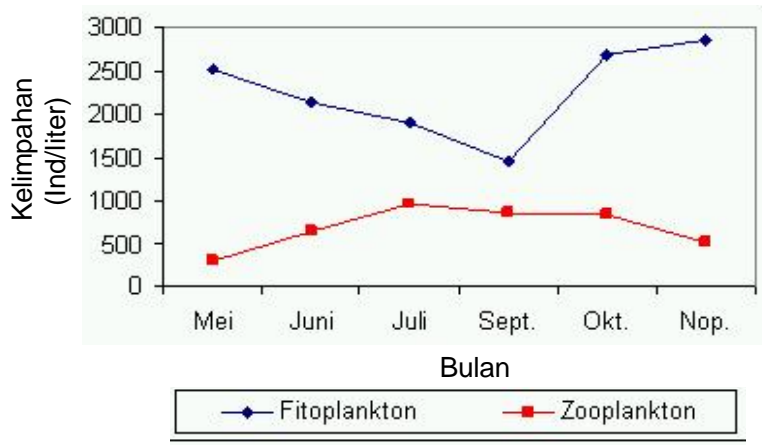

Gambar 3. Rata-rata kelimpahan fitoplankton dan zooplankton

Tabel 3. Kecepatan arus ( $\mathrm{m} /$ detik) pada setiap stasiun selama penelitian

\begin{tabular}{ccccccc}
\hline \multirow{2}{*}{ Stasiun } & \multicolumn{3}{c}{ Permukaan } & \multicolumn{2}{c}{ Kedalaman $25 \mathrm{~m}$} \\
\cline { 2 - 7 } & Juni & Juli & September & Oktober & Juni & Juli \\
\hline 1 & 0,105 & 0,056 & 0,058 & 0,161 & 0,068 & 0,058 \\
2 & 0,089 & 0,070 & 0,071 & 0,208 & 0,070 & 0,060 \\
3 & 0,075 & 0,076 & 0,100 & 0,147 & 0,090 & 0,058 \\
4 & 0,084 & 0,072 & 0,091 & 0,156 & 0,088 & 0,052 \\
5 & 0,072 & 0,070 & 0,078 & 0,208 & 0,072 & 0,062 \\
6 & 0,081 & 0,080 & 0,059 & 0,161 & 0,077 & 0,066 \\
7 & $*$ & 0,050 & 0,080 & 0,152 & $*$ & 0,060 \\
8 & 0,071 & 0,070 & 0,111 & 0,125 & 0,109 & 0,056 \\
9 & 0,083 & 0,082 & 0,159 & 0,088 & 0,067 & 0,064 \\
\hline
\end{tabular}

Tabel 4. Kelimpahan total fitoplankton pada setiap stasiun selama penelitian

\begin{tabular}{|c|c|c|c|c|c|c|}
\hline \multirow{2}{*}{ Stasiun } & \multicolumn{6}{|c|}{ Bulan } \\
\hline & Mei & Juni & Juli & September & Oktober & November \\
\hline 1 & 3681 & 1785 & 1500 & 2333 & 2007 & 1708 \\
\hline 2 & 3000 & 597 & 451 & 1854 & 4146 & 3986 \\
\hline 3 & 1465 & 3201 & 688 & 431 & 2361 & 4681 \\
\hline 4 & 3264 & 799 & 896 & 2744 & 4362 & 1389 \\
\hline 5 & 1563 & 2882 & 3882 & 1840 & 3111 & 1306 \\
\hline 6 & 2139 & 2861 & 3069 & 1299 & 1639 & 1576 \\
\hline 7 & & 1979 & 3458 & 654 & 2531 & 5438 \\
\hline 8 & & 1813 & 826 & 847 & 2028 & 3069 \\
\hline 9 & & 3208 & 2354 & 1069 & 2028 & 2507 \\
\hline Rata-rata & 2519 & 2125 & 1903 & 1452 & 2690 & 2851 \\
\hline
\end{tabular}


Tabel 5. Kelimpahan total zooplankton pada setiap stasiun pengamatan selama penelitian

\begin{tabular}{ccccccc}
\hline \multirow{2}{*}{ Stasiun } & \multicolumn{7}{c}{ Bulan } \\
\cline { 2 - 7 } & Mei & Juni & Juli & September & Oktober & November \\
\hline 1 & 288 & 699 & 1143 & 815 & 770 & 517 \\
2 & 119 & 479 & 1037 & 762 & 902 & 559 \\
3 & 402 & 680 & 773 & 718 & 827 & 480 \\
4 & 330 & 621 & 1032 & 992 & 977 & 488 \\
5 & 370 & 678 & 802 & 986 & 608 & 527 \\
6 & 268 & 725 & 861 & 849 & 866 & 529 \\
7 & & 649 & 988 & 759 & 779 & 473 \\
8 & & 683 & 876 & 779 & 793 & 482 \\
9 & & 545 & 1081 & 942 & 862 & 543 \\
Rata-rata & 296 & 640 & 955 & 845 & 820 & 511 \\
\hline
\end{tabular}

Tabel 6. Koefisien korelasi parsial dan p-value dalam regresi antara kelimpahan fitoplankton dan zooplankton dengan parameter lingkungan.

\begin{tabular}{lcccc}
\hline \multirow{2}{*}{ Parameter Lingkungan } & \multicolumn{2}{c}{ Fitoplankton } & \multicolumn{2}{c}{ Zooplankton } \\
\cline { 2 - 5 } Suhu & Koef. Korelasi Parsial & P-Value & Koef. Korelasi Parsial & P-Value \\
Salinitas & 0.3022 & 0.0184 & 0.1295 & 0.1850 \\
pH & -0.1389 & 0.1732 & 0.0058 & 0.4840 \\
Arus & 0.0869 & 0.2785 & -0.4340 & 0.0008 \\
Nitrat & 0.0831 & 0.2871 & 0.0154 & 0.4576 \\
Fosfat & 0.1597 & 0.1392 & $*$ & $*$ \\
Silikat & 0.2447 & 0.0469 & $*$ & $*$ \\
Fitoplankton & -0.0606 & 0.3413 & $*$ & -0.0712 \\
\hline
\end{tabular}

Catatan : cetak miring dalam kolom $p$-value menunjukkan signifikan $(\alpha=0.05)$

menunjukkan proporsi yang hampir sama dari waktu ke waktu.

Komposisi dan Kelimpahan Zooplankton. Jenis zooplankton yang didapatkan terdiri dari beberapa Filum diantaranya: Arthropoda (Copepoda dan Branchiopoda), Chaetognata, Molluska dan Annelida. Jenis yang paling sering ditemukan dengan kelimpahan yang relatif tinggi adalah golongan copepoda. Kelimpahan zooplankton rendah pada bulan Mei dengan rata-rata 296 individu/L, dan mencapai nilai terendah di St. 2 dengan kelimpahan 119 individu /L (Tabel 5).

Populasi zooplankton didominasi oleh Kelas Crustaceae golongan copepoda. Beberapa jenis copepoda yang ditemukan dalam jumlah dan frekuensi kemunculan yang cukup tinggi adalah Acartia, Oithona, Nauplii copepoda, dan Tartonus. Hubungan antara kelimpahan zooplankton dengan fitoplankton menunjukkan pergantian fungsi antara keduanya, yang menyebabkan zooplankton dikontrol oleh kelimpahan fitoplankton pada suatu waktu, dan pada waktu lainnya kelimpahan fitoplankton dikontrol oleh kelimpahan zooplankton (Gambar 3). Oleh karena itu hasil analisis regresi secara simultan dalam waktu yang bersesuaian pada setiap stasiun per bulan antara kelimpahan zooplankton dengan fitoplankton tidak memperlihatkan korelasi yang signifikan.

Hubungan Antara Kelimpahan Plankton dengan Parameter Oseanografi. Hasil analisis regresi antara kelimpahan fitoplankton $(\mathrm{Y})$ dengan parameter lingkungan menunjukkan bahwa suhu dan fosfat yang signifikan berkorelasi linier dengan kelimpahan fitoplankton dengan korelasi yang sangat lemah $\left(R^{2}=0,20\right)$. Hasil regresi antara zooplankton dengan parameter lingkungan (kecuali nutrien) dan kelimpahan fitoplankton menunjukkan bahwa hanya $\mathrm{pH}$ perairan yang signifikan berkorelasi linier negatif dengan kelimpahan zooplankton dengan nilai korelasi yang sangat rendah $\left(R^{2}=0,19\right)$. Koefisien korelasi parsial setiap parameter dengan kelimpahan fitoplankton dan zooplankton dalam analisis regresi disajikan dalam Tabel 6.

Kandungan klorofil-a. Rata-rata kandungan klorofil-a di permukaan berkisar antara $0,075 \mathrm{mg} / \mathrm{m}^{3}$ pada bulan September sampai dengan $0,229 \mathrm{mg} / \mathrm{m}^{3}$ 
Tabel 7. Rata-rata \pm simpangan baku (SB) kandungan klorofil-a $\left(\mathrm{mg} / \mathrm{m}^{3}\right)$ berdasarkan kedalaman

\begin{tabular}{|c|c|c|c|c|c|c|c|c|c|c|c|c|}
\hline \multirow{3}{*}{$\frac{\text { Bulan }}{\text { Mei }}$} & \multicolumn{4}{|c|}{ Permukaan } & \multicolumn{4}{|c|}{25 meter } & \multicolumn{4}{|c|}{50 meter } \\
\hline & \multicolumn{3}{|c|}{ Rata-rata \pm SB } & \multirow{2}{*}{$\frac{n}{6}$} & \multicolumn{3}{|c|}{ Rata-rata \pm SB } & \multirow{2}{*}{$\frac{n}{6}$} & \multicolumn{3}{|c|}{ Rata-rata \pm SB } & $\mathrm{n}$ \\
\hline & 0,229 & \pm & 0,096 & & 0,148 & \pm & 0,061 & & 0,265 & & 0,000 & 1 \\
\hline Juni & 0,111 & \pm & 0,040 & 9 & 0,095 & \pm & 0,080 & 9 & 0,080 & \pm & 0,056 & 3 \\
\hline Juli & 0,129 & \pm & 0,128 & 8 & 0,353 & \pm & 0,384 & 8 & 0,106 & \pm & 0,102 & 4 \\
\hline September & 0,078 & \pm & 0,035 & 9 & & & & & & & & \\
\hline Oktober & 0,147 & \pm & 0,071 & 9 & 0,138 & \pm & 0,056 & 9 & 0,043 & & 0,037 & 4 \\
\hline November & 0,156 & \pm & 0,079 & 9 & 0,126 & \pm & 0,063 & 9 & 0,120 & \pm & 0,061 & 4 \\
\hline
\end{tabular}

Catatan : data pada kedalaman $75 \mathrm{~m}$ tidak disajikan karena hanya terdapat satu data.

pada bulan Mei. Kandungan klorofil-a pada permukaan berkisar antara $0,037-0,383 \mathrm{mg} / \mathrm{m}^{3}$. Rata-rata kandungan klorofil-a pada kedalaman $25 \mathrm{~m}$ lebih tinggi dibandingkan dengan di permukaan (Tabel 7).

\section{Laju Pertumbuhan dan Pemangsaan} Fitoplankton. Kandungan klorofil-a yang didapat dari percobaan ini berkisar antara $0,142-2,198 \mathrm{mg} / \mathrm{m}^{3}$ pada air yang disaring dan $0,062-0,328 \mathrm{mg} / \mathrm{m}^{3}$ pada air yang tidak disaring. Plot antara kandungan klorofil-a dengan lama waktu inkubasi menunjukkan bahwa kandungan klorofil-a dari air yang disaring cenderung meningkat dengan bertambahnya lama inkubasi dengan peningkatan sekitar $0,0529 \mathrm{mg} / \mathrm{m}^{3}$ setiap jamnya. Pertumbuhan fitoplankton ini merupakan pertumbuhan yang terlihat. Setelah dikurangi dengan kandungan klorofil dari sampel yang tidak disaring maka diperoleh plot pertumbuhan fitoplankton sebenarnya dengan kecenderungan meningkatnya kandungan klorofil-a sekitar 0.0334 sampai dengan $0.0361 \mathrm{mg} / \mathrm{m}^{3}$ (Gambar 4), atau bisa dikatakan fitoplankton di perairan ini pada saat penelitian tumbuh sebesar 3,3-3,6\%.

Hasil Tangkapan Ikan dan Struktur Jenjang Trofik. Jumlah dan Komposisi Jenis Ikan Tangkapan. Ikan yang tertangkap dengan bagan Rambo terdiri dari beberapa jenis yang tergolong pelagis kecil. Beberapa jenis tangkapan dominan yang bernilai ekonomis adalah ikan teri (Stolephorus commersoni, dan Stolephorus sp. lainnya), ikan tembang (Sardinella fimbriata), ikan pepetek (Leiognathus sp), ikan layang

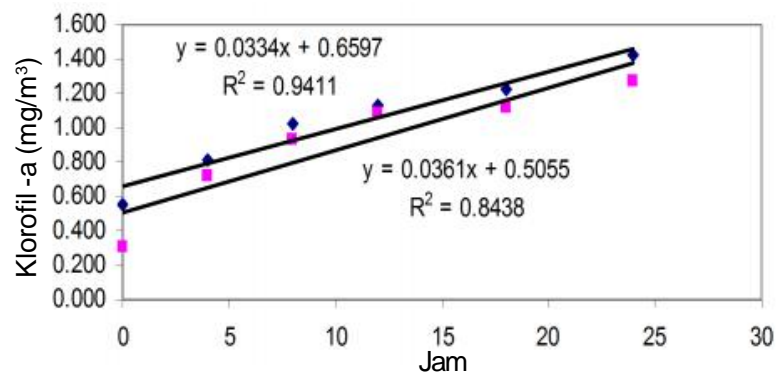

Gambar 4. Kandungan klorofil-a yang dihasilkan dari pertumbuhan fitoplankton di dua lokasi selama penelitian.
(Decapterus ruselii dan Decapterus malrosoma), dan ikan kembung (Rastrelliger kanaguarta). Golongan non ikan (molluska) yang sering tertangkap dengan nilai ekonomis yang cukup bagus adalah cumi-cumi (Loligo sp.). Jenis ikan yang banyak tertangkap pada saat penelitian adalah teri, tembang, dan pepetek.

Struktur Jenjang Trofik dan Kebiasaan Makan. Jenis ikan yang diamati isi lambungnya selama penelitian diantaranya adalah ikan teri, tembang, pepetek, dan layang. Hasil analisis makanan dengan perangkat lunak TrophLab2Kmenunjukkan bahwa ikan pelagis yang dominan tertangkap dengan bagan berada dalam posisi jenjang trofik yang berbeda, masingmasing adalah ikan teri $(2,76 \pm 0,25)$, ikan tembang $(3,13 \pm 0,37)$, ikan pepetek $(3,23 \pm 0,47)$, dan ikan layang $(3,60 \pm 0,56)$. Beberapa ikan yang tergolong ikan omnivor dan karnivor lainnya seperti layur, tongkol, tenggiri, dan barracuda memiliki jenjang trofik yang lebih tinggi namun tidak dianalisis. Ini disebabkan karena volume tangkapan jenis ikan tersebut relatif kecil dengan frekuensi kemunculan yang rendah.

Model Dinamik Jenjang Trofik. Komponen model ini terdiri dari lima kompartemen (komponen) utama yaitu fitoplankton, zooplankton, ikan planktivor, ikan omnivor, dan ikan karnivor. Setiap komponen tersebut merupakan sub-model yang dirangkaikan berdasarkan hubungan pemangsaan dari antar komponen dalam model.

Desain dasar model dinamik ini mengkombinasikan antara proses biologis dan faktor fisik (oseanografi). Proses biologis yang terjadi pada setiap komponen membentuk transfer materi melalui proses pemangsaan yang membentuk rantai dan jaring makanan (Mathews et al., 1993; Pimm et al., 1982). Fitoplankton dimakan oleh zooplankton, ikan planktivor dan omnivor, zooplankton dimangsa oleh ikan planktibor dan omnivor, ikan planktivor dimakan oleh ikan omnivor dan karnivor dan ikan omnivor dimangsa oleh ikan karnivor. 
Dalam model ini komponen ikan planktivor terdiri dari populasi ikan teri (Stolephorus spp) dan ikan tembang (Sardinella spp). Komponen ikan omnivor terdiri dari ikan pepetek (Leiognathus sp), ikan layang (Decapterus spp), dan ikan kembung (Rastrelligerspp). Ikan karnivor diwakili oleh ikan selar (Selatoides spp). Model lengkap menggunakan program Stella ditunjukkan dalam Gambar 5.

Batasan dan Asumsi Model. Model dinamik jenjang trofik yang dibuat dalam penelitian ini memiliki beberapa batasan sesuai dengan ruang lingkup kajian penelitian. Meskipun model ini menyangkut jenjang trofik tetapi tidak semua komponen biota yang ada dalam lokasi penelitian dimasukkan dalam model, misalnya komponen detritus, bakteri dan bahan organik, dan rantai makanan dalam sistem bentik. Untuk mencapai tujuan penelitian ini dengan segala keterbatasan yang ada maka dalam model ini dibuat beberapa asumsi yang memungkinkan model ini dapat

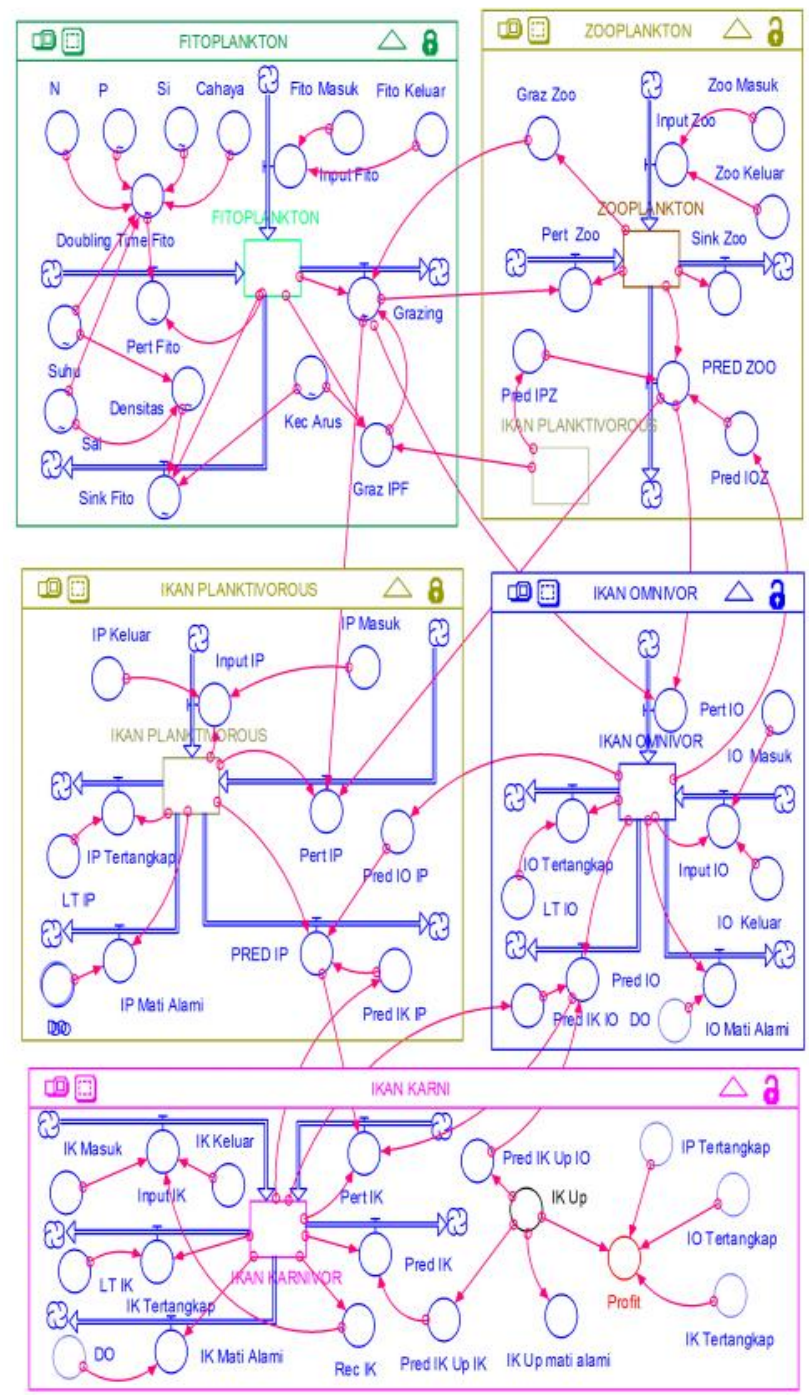

Gambar 5. Diagram transfer materi dari fitoplankton sampai ke karnivor. dijalankan. Beberapa asumsi tersebut adalah sebagai berikut:

Proses fisik terjadi dalam kondisi normal dan mengikuti pola siklus tahunan yang sama, dan tidak terjadi perubahan ekstrim pada salah satu atau beberapa parameter oseanografi yang menyebabkan perubahan ekstrim pertumbuhan fitoplankton dan zooplankton.

Tidak terjadi perubahan biomassa yang cukup besar akibat migrasi populasi ikan secara besar yang menyebabkan perubahan jejaring dan rantai makanan dalam wilayah yang dimodelkan. Biomassa ikan yang keluar dan masuk ke dalam sistem yang dimodelkan dianggap sama. Jumlah ikan yang tertangkap proporsional dengan kelimpahan populasi ikan di dalam perairan

Beberapa tetapan atau koefisien yang diadopsi dari lokasi lain dan atau dari kajian pustaka yang digunakan dalam model tidak terlalu jauh berbeda dengan kondisi sebenarnya dalam lokasi yang dimodelkan.

Hasil run. Hasil run dari model tersebut dapat dilihat pada Gambar 6 untuk penangkapan sebesar seperti yang dilakukan di lokasi pada saat penelitian. Dengan anggapan bahwa aktivitas baru dimulai, penangkapan sebesar yang sekarang dilakukan akan mengakibatkan tangkap-lebih pada ikan planktivor (IP Tertangkap) pada bulan ke 26, dan akan terus demikian pada waktu-waktu berikutnya. Hal ini mengakibatkan menurunnya makanan ikan omnivor sehingga tidak mendukung populasi ikan omnivor untuk periode selanjutnya. Akibatnya jumlah ikan omnivor yang tertangkap (10 Tertangkap) pada puncak musim (sekitar bulan ke-32) penangkapan menurun lebih rendah dari jumlah tangkapan biasanya. Sebaliknya, Gambar 7 menunjukkan bahwa kalau penangkapan dilakukan sebesar setengah dari penangkapan sekarang, pada bulan ke 29 tangkapan ikan planktivor juga cukup tinggi tetapi segera menurun pada bulan-bulan berikutnya dibawah laju tangkapan biasanya sehingga beberapa bulan kemudian, yaitu pada bulan ke 31 atau 32, kondisinya akan membaik akibat tekanan tangkapan yang lebih rendah. Hal ini menyebabkan tersedianya makanan yang mendukung populasi ikan omnivor sehingga jumlah tangkapan ikan omnivor pada puncak musim relatif lebih tinggi. Dalam jangka lama, apabila kedua skenario itu dijalankan maka jelas hasil pada skenario kedua memberikan hasil yang lebih baik dan 


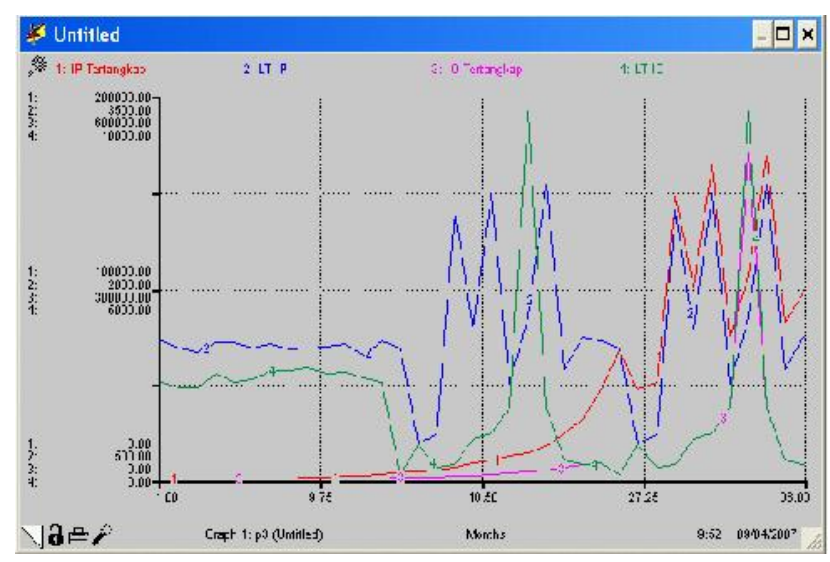

Gambar 6. Hasil "run" model kalau penangkapan sebesar penangkapan sekarang

cenderung berkelanjutan akibat penangkapan yang dilakukan tidak terlalu besar pada ikan jenjang trofik yang rendah. Keadaan yang ditunjukkan pada Gambar 6 dan 7 hanya berlaku untuk ikan planktivor dan omnivor. Untuk ikan karnivor, hasilnya berbeda dan masih dicari penyebabnya.

\section{KESIMPULAN}

Model yang dibangun berdasarkan data yang dikumpulkan selama penelitian untuk ikan planktivor dan omnivor logikanya bisa diterima berdasarkan simulasi yang dilakukan untuk penangkapan sebesar yang sekarang dan penangkapan sebesar setengah dari penangkapan yang sekarang. Dari hasil simulasi tersebut dapat disimpulkan bahwa salah satu cara untuk menangani tangkap-lebih di Selat Makassar sekarang ini adalah dengan mengurangi jumlah tangkapan menjadi setengah dari tangkapan sekarang. Meskipun demikian, model ini tidak berlaku untuk ikan karnivor. Masih perlu perbaikan, pengembangan serta pemakaian data dan konstanta yang lebih akurat sebelum model ini dianggap benar-benar sudah memadai.

\section{UCAPAN TERIMA KASIH}

Penulis mengucapkan terima kasih kepada Direktorat Jenderal Pendidikan Tinggi, Departemen

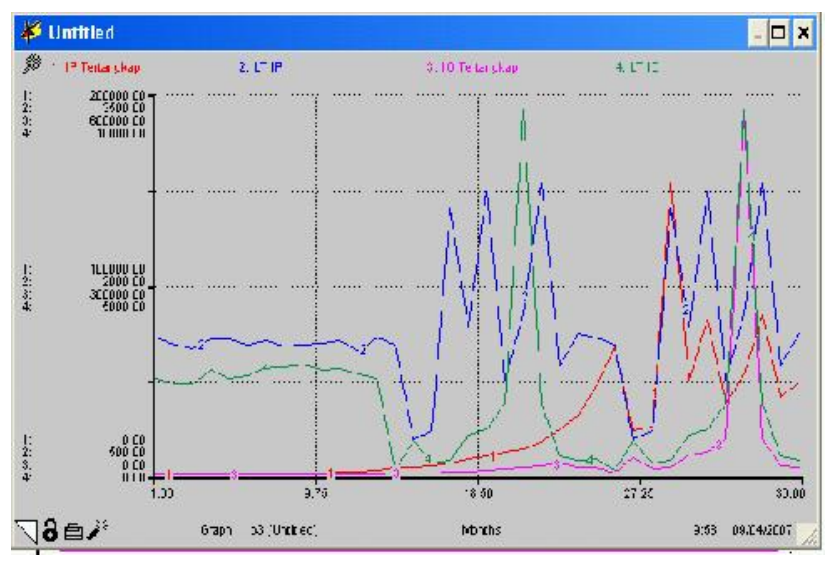

Gambar 7. Hasil "run" model kalau penangkapan sebesar setengah dari penangkapan sekarang

Pendidikan Nasional, yang telah membiayai penelitian ini lewat Program Penelitian Hibah Bersaing dengan Surat Perjanjian Pelaksanaan Nomor 026/SPPP/ PP_PM/DP3M/IV/2005 Tanggal 11 April 2005 dan Nomor 317/SP3/PP/DP2M/II/2006 Tanggal 1 Februari 2006.

\section{DAFTAR PUSTAKA}

Arimoto, T., Sakai, H., Baskoro, M.S., Darmawan, Sondita, F.A., Jaya, I, \& Wisudo, S.H. 2001. Fishing Technology Manual Series 1; Light Fishing in Japan and Indonesia, The JSPS-DGHE International Workshop 2001. TUF International JSPS Project, Tokyo University of Fisheries, Japan. Vol 11.

Costanza, R., Sklar, F.H., \& White, M.L. 1990. Modelling Coastal Landscape Dinamycs. Bioscience 40(2).

Christensen, V. \& Pauly, D. 1993. Trophic Models of Aquatic Ecosistems. Manila: ICLARM Contribution No. 638.

Kaswadji, R.F, Widjaja, F., \& Wardiatno, Y. 1993. Produktivitas Primer dan Laju Pertumbuhan Fitoplankton di Perairan Pantai Bekasi. Jurnal IImu-ilmu Perairan dan Perikanan Indonesia 2(1):1-15.

Mathews, C.P. 1993. Productivity and energy flows at all trophic levels in the River Thames. England: Mark 2. Di dalam: Christensen, V. \& Pauly, D. (eds.). Trophic models of aquatic ecosystems. ICLARM Conf. Proc. Halaman 161-171.

Naito, W., Miyamoto, K., Nakanishi, J., Masunaga, S., \& Bartell, S.M. 2001. Application of an Ecosystem Model for Aquatic Ecological Risk Assesment of Chemical for a Japanese Lake. Water Research 36: 1-14.

Parsons, T.R. \& Kessler, T.A. 1987. An Ecosystem Model for the Assesment of Plankton Production in Relation to the Survival of Young Fish. J. Plank. Res. 9(1): 125-137.

Pauly, D., Christensen, V., Froese, R. \& Palomares, M.L. 2000. Fishing down aquatic food webs. American Scientist, 88: 46-51.

Pimm, S.L. 1982. Food webs.Chapman and Hall. London: Great Britain. 